\title{
Thinkering through Experiments: Nurturing Transdisciplinary Approaches to the Design of Testing Tools
}

\author{
Kathryn B. Francis ${ }^{1,4 \#^{*}}$ \\ , Agi Haines ${ }^{1,2 \# * *}$ \\ (iD) , \& Raluca A. Briazu1,3\#*** \\ ${ }^{1}$ Cognovo \\ 2 Transtechnology Research, Plymouth University, UK \\ 3 School of Psychology, Plymouth University, UK \\ 4 Department of Philosophy \& School of Psychology, University of Reading, UK \\ \# Denotes equal contribution. \\ *KathrynBFrancis@CogNovo.eu \\ **agi@agihaines.com \\ ***Raluca.Briazu@CogNovo.eu
}

Received 12 May 2017; accepted 26 September 2017; published 21 November 2017.

\begin{abstract}
In order to assess and understand human behavior, traditional approaches to experimental design incorporate testing tools that are often artificial and devoid of corporeal features. Whilst these offer experimental control in situations in which, methodologically, real behaviors cannot be examined, there is increasing evidence that responses given in these contextually deprived experiments fail to trigger genuine responses. This may result from a lack of consideration regarding the material makeup and associations connected with the fabric of experimental tools. In a twoyear collaboration, we began to experiment with the physicality of testing tools using the domain of moral psychology as a case study. This collaboration involved thinkering and prototyping methods that included direct contact and consideration of the materials involved in experimentation. Having explored the embodied nature of morality, we combined approaches from experimental psychology, moral philosophy, design thinking, and computer science to create a new testing tool for simulated moral behavior. Although the testing tool itself generated fruitful results, this paper considers the collaborative methodology through which it was produced as a route to highlight material questions within psychological research.
\end{abstract}

Keywords: collaboration; embodiment; methodology; moral psychology; prototyping; thinkering. 
In this paper, we suggest that prototyping techniques from arts and design practice can enrich ideation when developing fresh or novel research questions. The act of prototyping discussed here has offered insights arising through an on-going collaboration that explored thinking through making ${ }^{1}$ to create a physical tool for psychology experimentation.

\section{Thinking through Making}

Thinking through writing is part and parcel of many academic disciplines. However, in the sciences, thinking through making is less explored. This is somewhat surprising, given that in the experimental sciences, the process of designing methodology is integral to the research process. For a psychologist, designing a questionnaire, for example, will involve the formulation and psychometric assessment of items (i.e., questions) designed to measure a particular construct (Kline, 2015). For a graphic designer on the other hand, designing a questionnaire will involve the consideration of font, paper, layout, and coloring. Both the design of the questions and the design of the physical page can have an effect on the outcome (e.g., Christensen, Flexas, Calabrese, Gut, \& Gomila, 2014).2 The process of "making"3 experimental materials, in terms of its ability to engender new ideas for research, is particularly uncommon in the social sciences. Although psychology acknowledges that interacting with the materiality of our environment is crucial to the way we develop our ability to think and act (e.g., see Piaget, 1976), the integration of material culture in psychology research is still "terra incognita" (Moro, 2015). What often remains unexplored in experimental psychology is the link between this direct engagement with physical materials and the measurement of phenomena (Briazu, Francis, \& Haines, 2015). Introducing questions concerned with making can motivate new inquiries in experimental science; how might the physical attributes and stylistic decisions that form the testing tool detach or engage the participant, subsequently influencing the outcome of interest?

\footnotetext{
${ }^{1}$ A concept derived from Ingold's Making: Anthropology, Archaeology, Art and Architecture in which he argues that making builds knowledge (Ingold, 2013).

2 This notion that how we interpret something, influences how we act, is conveyed in a variety of concepts across psychology and sociology including the Thomas theorem, the Matthew effect, and the Placebo Effect (e.g., DeNora, 2014).

${ }^{3}$ In this case we consider making as exploratory poiesis, as Donahue writes "to make is to explore materials with one's own hands and body as an essential tool, emphasizing the relationship between tool and material and what it can offer the creative process" (Donahue, 2014, p. 7).
} 


\section{Dilemmas of Morality and Measurement}

In previous work, we have considered the extent to which incorporating rhetorical and abstracted testing tools, such as questionnaires, can allow approximation of realworld phenomena (Briazu et al., 2015). More specifically, in the domain of moral psychology, we outlined concerns regarding the hypothetical nature of moral dilemmas, seeking to approximate moral decision-making. Using the footbridge dilemma ${ }^{4}$ as a case study (see Figure 1), we challenged the representation of moral conflicts in textbased vignettes and the dichotomous nature of the questions following these, seeking to measure morality. ${ }^{5}$

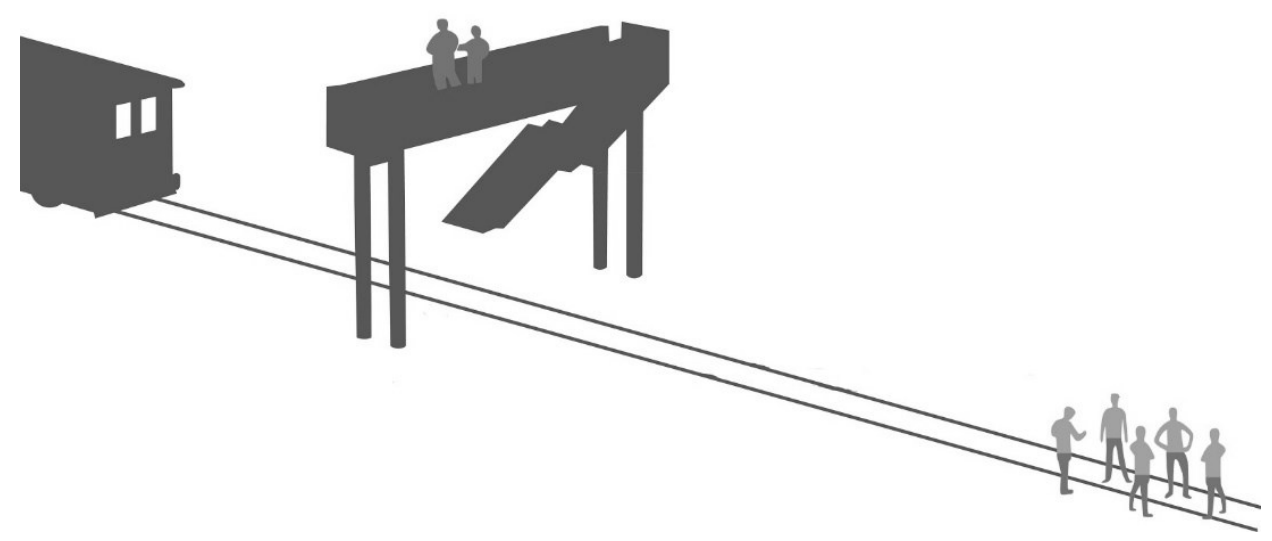

Figure 1. Diagram depicting the footbridge dilemma.

Crucially, although these rhetorical materials have provided the foundation for many models of moral decision-making, the materials themselves often fail to uncover valid insights into how people would react to and feel in moral dilemmas, given that they motivate a certain degree of disengagement (Briazu et al., 2015; Terbeck \& Francis, in press). By introducing inductive approaches from design research to debates concerning the artificial nature of experimental materials and by adopting a thinking through making approach, we considered the creation of a testing tool that

\footnotetext{
${ }^{4}$ In the classic footbridge dilemma, an individual must decide whether to push a large person off a footbridge in order to stop a runaway trolley from killing five workers on the track below (Foot, 1978; Thomson, 1976).

5 These questions often follow the format of a judgment question ("Is it morally acceptable to push the person off the bridge in order to save the five workers on the tracks?") or action-choice question ("Would you do it?") and are followed with a dichotomous scale ("Yes" or "No") or ordinal response scale (such as a Likert scale).
} 
could "establish a physical coupling between experiment and participant" (Briazu et al., 2015, p. 29). In short, our project sought to interrogate and prioritize the physicality of the footbridge dilemma. While previous research had attempted to depart from theoretical instances of these moral dilemmas by generating visually salient scenarios using virtual reality (VR; see Figure 2; e.g., Francis et al., 2016; Patil, Cogoni, Zangrando, Chittaro, \& Silani, 2014), this research has yet to consider the significance of physical salience in moral dilemmas; what would happen if making a moral decision felt real? ${ }^{6}$ This is where a practice-based methodology can offer insights. We examined the function of tactile feedback in resembling the embodiment of realistic actions. Adopting this approach, thus, laid the foundations for the development of an interdisciplinary moral testing tool, shaped by aesthetic realism, haptic momentum, and tactile sensation (Briazu et al., 2015).

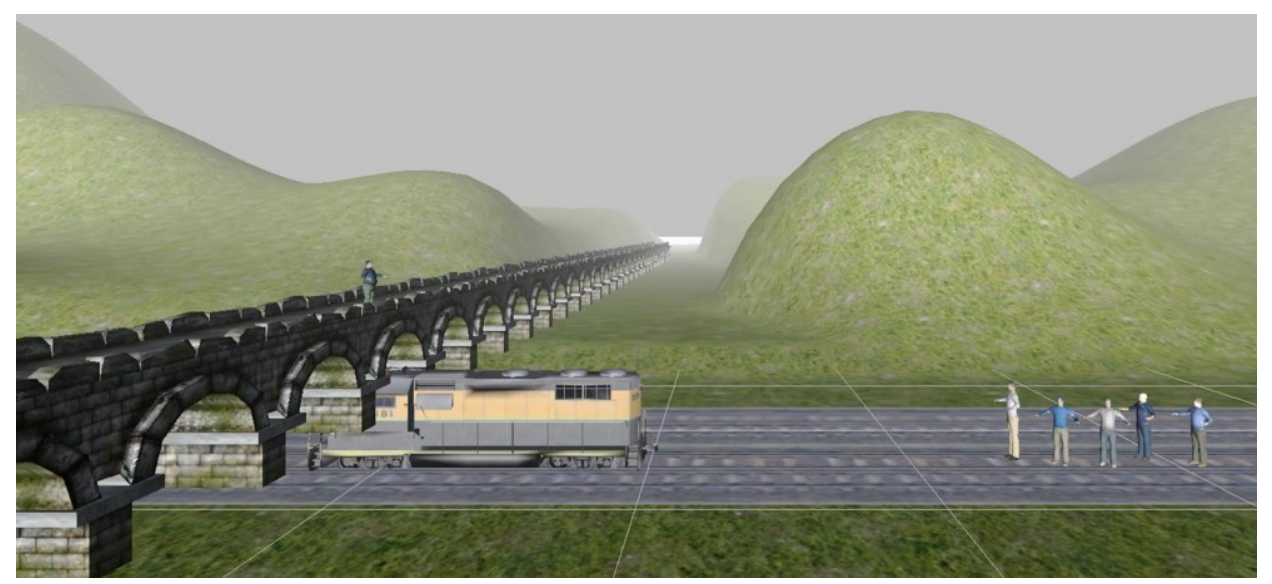

Figure 2. Model of footbridge dilemma during development in virtual reality. Note. This is not the perspective from which the participant views the virtual scenario.

\section{Distorted Dimensions}

Using our initial inquiry as motivation, we began to work on "Distorted Dimensions," an installation designed to situate the measurement of simulated moral actions in corporeal and tangible environments. In the installation, a virtuallyconstructed footbridge dilemma was simulated using the Oculus Rift and a life-like sculpture of the stranger on the footbridge was built to echo its virtual counterpart. The design of the sculpture or testing tool, which was the focal point of Distorted

\footnotetext{
${ }^{6}$ Using "VR" as a testing material in this case can be challenging as it is often synonymous with "gaming," a problematic coupling for psychology experiments that seek to measure genuine as opposed to detached responses.
} 
Dimensions, pivoted around three central aims. Firstly, the mechanics of the sculpture were designed for interaction, allowing the sculpture to replace typical testing tools such as joystick controllers (Francis et al., 2016; Patil et al., 2014). Secondly, aesthetic realism and tactile sensation were simulated through expandable foam and platinum grade silicone. Finally, the sculpture's weight allowed for the haptic simulacrum of a body free-falling if pushed (see Figure 3). Utilizing this tool allowed us to measure realistic simulations of moral actions and, unlike previous research, also permitted the examination of embodiment and personal force in moral decision-making (Francis et al., 2017). ${ }^{7}$

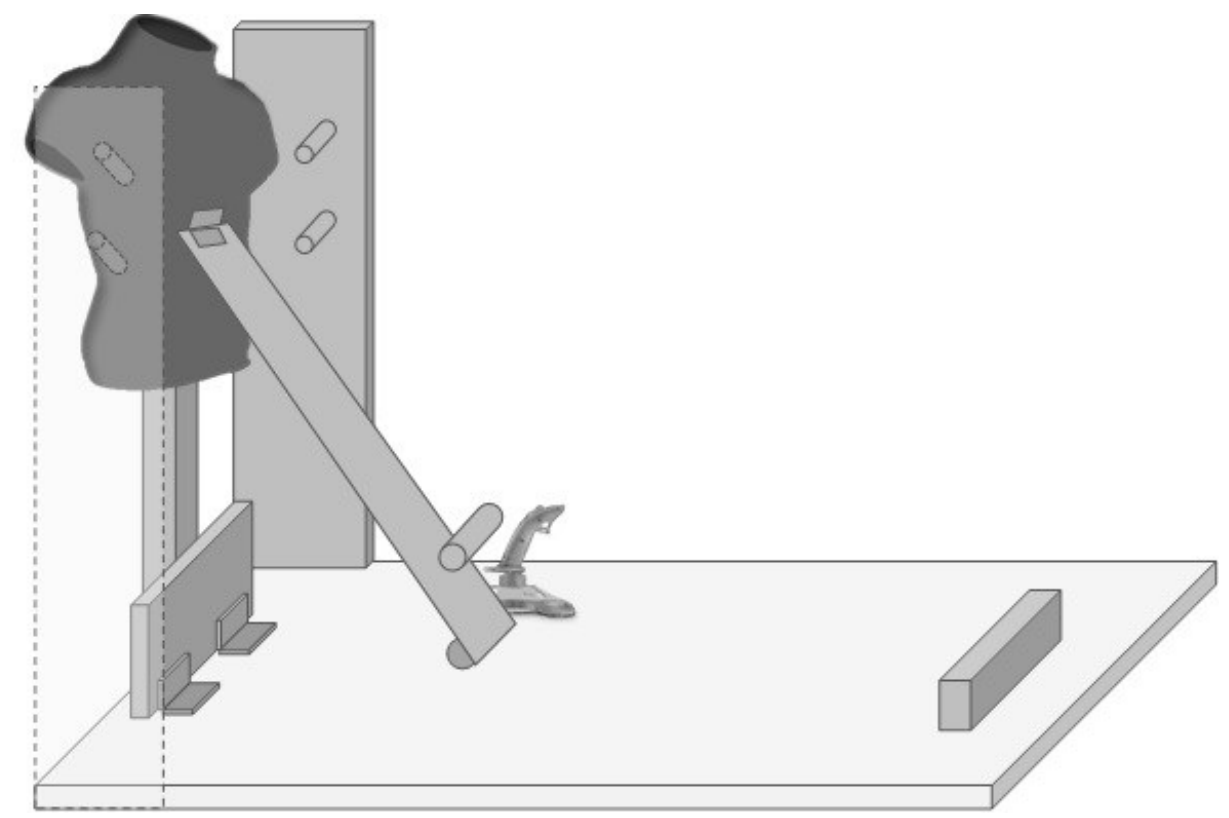

Figure 3. Diagram of the sculpture component of Distorted Dimensions. If pushed, the sculpture's torso would fall forward along the runner, pushing the joystick forward.

\footnotetext{
${ }^{7}$ From a psychological perspective, arguably we are attempting to enhance sensory similarity (a component of ecological validity or the concept of making an experiment "look" and "feel" more real). Importantly, in the context of this work, sensory similarity does not infer "external validity" (the concept that responses observed in a laboratory setting can be generalized to the real-world setting). We are not suggesting that we are pursuing a "hyperreality" in the making of our experimental tools, or the blurring of lines between reality and simulation. Instead, we are attempting to create an action which is hyperreal, ("the generation by models of a real without origin or reality," Baudrillard, 1994. p. 1) in that it is hard to distinguish from true-to-life action.
} 


\section{The Making of Morality}

While the sculpture advanced our understanding of simulated moral actions, these research aims were not the sole outcomes of Distorted Dimensions. There were a number of other aspects at play during the process of the installation's production. In the same way that Christopher Small describes music as being an ideal figment of what he describes as the action of "musicking," (Small, 1998) our sculpture was a figment of the making. The sculpture itself contains traces of decisions that were made during our collaboration and these are visible in its form. In the action of making, aspects of our environment and our personalities played a role in the physical prototype; external conditions dented the trajectory of the making process, altering what it became. In our development of the sculpture, our aim was to facilitate, and not hinder, the flow of the making process and the materials that we were using. Although the object was successful in achieving the initial research aims described above, it was our regard for the making process that prompted and nurtured our insights into collaboration and material (see Figure 4).

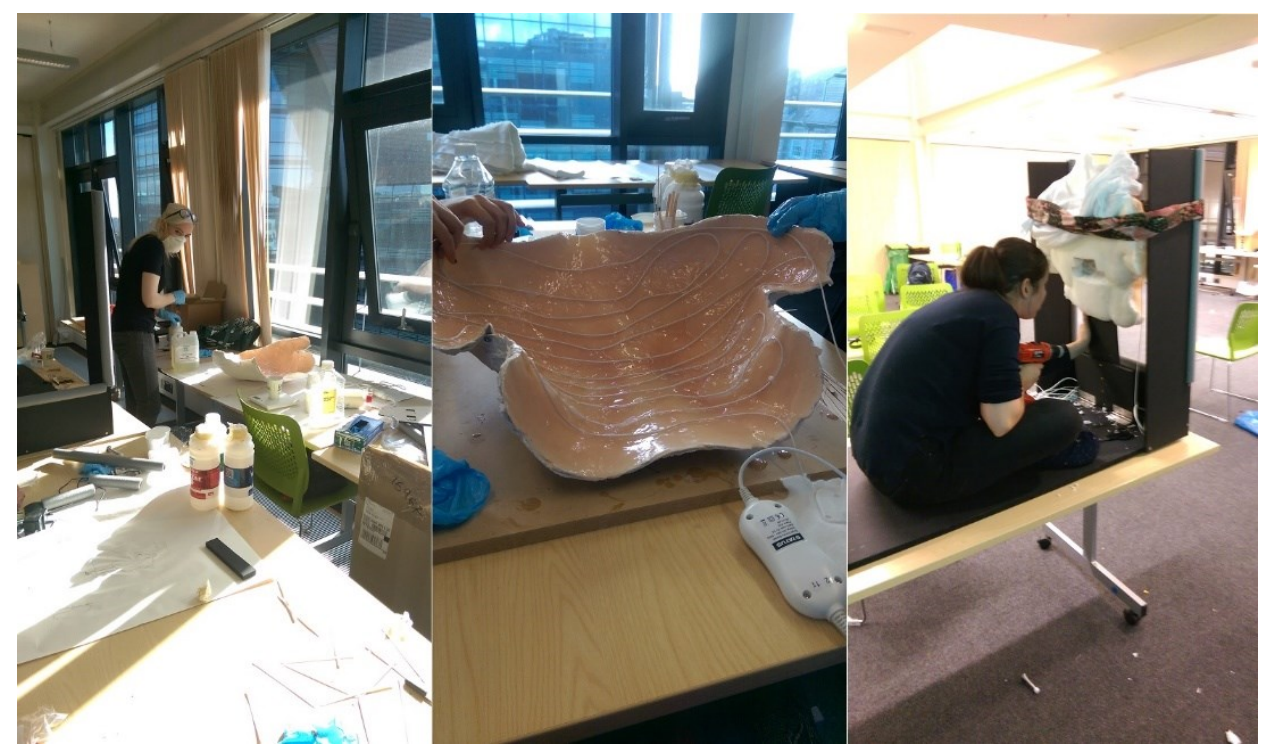

Figure 4. Images of the dynamic making process.

It was an active engagement with the materials that shaped our experimental device, allowing for a more thorough construction of the participant's experience and understanding of the topic at hand. ${ }^{8}$ Crucially, in order to create an object that can

\footnotetext{
${ }^{8}$ As Latour suggests, "thinking with eyes and hands" and in our case also "things" (Latour, 1990).
} 
"speak" to an audience in a sensory fashion, we should focus on understanding the agency of the materials that we are using. After all, a practitioner must work with their material to produce form. Ingold (2010) likens this to a carpenter following the grain of the wood with an axe in order to generate a favorable cut. The makeup of the materials that we are using also has a "grain." For example, the controllers, questionnaires, silicones and VR in our installation are not inert and it is imperative to consider all of these materials as dynamic. This "grain" represents the complexity of materiality that is often neglected in experimental science, perhaps as a result of scientific reductionism and its motivation to form explanations of the natural world. Taking the complexity of materials into account, the interaction between sculpture and the virtual environment allowed us to shape an experience that was far more provocative and analogous to real-life action than what might be construed by a testing tool that had not been considered in this way. From an experimental point of view, understanding this "grain," becomes pivotal in creating the bond between participant and experiment.

\section{Collaborative Thinkering}

As John Seely Brown suggests, the process of prototyping in this fashion might be described as "thinkering." Antonelli (2011) describes this as a form of productive tinkering that involves testing and adjusting with "like-minded spirits and engaging with the world in an open, constructive collaboration" (para. 1). Commonplace strategies for problem-solving and ideation are often constrained by disciplinary norms, but through "collaborative bricolage or tinkering" (Innes \& Booher, 1999, p. 12), here defined as thinkering, novel strategies for ideation can develop through "learning-by-doing" (e.g., Donahue, 2014) as group members combine existing ideas, methods, and scenarios to create something new (Innes \& Booher, 1999). This collaborative component has been paramount in our work, in both its processes and outcomes; the iterative process of making was invaluable in fostering our creativity and prompting discovery (Donahue, 2014). Most importantly, this process allowed for the emergence of a dynamic system which enabled an open and judgment-free exchange of ideas between disciplines (e.g., Donahue, 2014). In our collaboration, thinkering involved "interacting with a web of knowledge, tools, and distributed communities of practice" (Brown, 2009, p. 4), a working process that fostered a collaborative attitude which was both inspiring and motivating.

Crucially, it seems that it is the willingness to embrace interdisciplinary approaches openly that can enrich fields of research that are so often constrained by single disciplinary approaches. To date, the methods that enable designers and scientists to collaborate in scientific research have been largely overlooked (Peralta \& Moultrie, 2010). We propose that thinkering can provide a stage for the manifestation of humor, personal empathy, and proximity between researchers, which Epstein (2005) 
regards as essential for collaboration. After all, perhaps the most important aspect of thinkering for the $21^{\text {st }}$ century is "listening with humility with an open mind" (Brown, 2009 , p. 8), and we suggest that this approach be unobstructed by disciplinary boundaries. Using collaborative thinkering in this way has allowed us to examine and consider our interactions with the physical material of the world around us, generating mutual insights into psychology, philosophy, and design.

\section{Acknowledgements}

The authors would like to thank Dr. Thea Ionescu, Dr. Joanna Griffin, and Dr. Gintare Zaksaite for providing constructive feedback on earlier versions of the present work.

\section{References}

Antonelli, P. (2011) States of design 03: Thinkering. Domus, 948. Retrieved from: http://www.domusweb.it/en/design/2011/07/04/states-of-design-03-thinkering.html

Baudrillard, J. (1994). Simulacra and simulation. Ann Arbor, MI: University of Michigan Press.

Briazu, R. A., Francis, K. B., \& Haines, A. (2015, September). The affective embodiment of testing tools and their influence on experimental outcomes. Paper presented at the Off The Lip - Trandisciplinary Approaches to Cognitive Innovation, Plymouth, UK. Retrieved from http://hdl.handle.net/10026.1/4271

Brown, J. S. (2009). Learning 2.0: The big picture [PDF presentation]. Retrieved from http://www.johnseelybrown.com/learning2.pdf

Christensen, J. F., Flexas, A., Calabrese, M., Gut, N. K., \& Gomila, A. (2014). Moral judgment reloaded: A moral dilemma validation study. Frontiers in Psychology, 5, 1-18. doi:10.3389/fpsyg.2014.00607

Epstein, S. L. (2005). Making interdisciplinary collaboration work. In S. J. Derry, C. D. Schunn, \& M. A. Gernsbacher (Eds.), Interdisciplinary collaboration: An emerging cognitive science (pp. 245-263). Mahwah, NJ: Lawrence Erlbaum Associates.

Foot, P. (1978). Virtues and vices and other essays in moral philosophy. Berkeley, CA: University of California Press.

Francis, K. B., Howard, C., Howard, I. S., Gummerum, M., Ganis, G., Anderson, G., \& Terbeck, S. (2016). Virtual morality: Transitioning from moral judgment to moral action? PLoS One, 11(10), 1-22. doi:10.1371/journal.pone.0164374

Francis, K. B., Terbeck, S., Briazu, R. A., Haines, A., Gummerum, M., Ganis, G., \& Howard, I. S. (2017). Simulating moral actions: An investigation of personal force in virtual moral dilemmas. Scientific Reports, 7. doi:10.1038/s41598-017-13909-9

Innes, J. E., \& Booher, D. E. (1999). Consensus building as role playing and bricolage: Toward a theory of collaborative planning. Journal of the American Planning Association, 65, 9-26. 
Ingold, T. (2010). The textility of making. Cambridge Journal of Economics, 34, 91-102.

Ingold, T. (2013). Making: Anthropology, archaeology, art and architecture. Oxford, UK: Routledge.

Kline, P. (2015). A handbook of test construction: Introduction to psychometric design. New York, NY: Routledge.

Latour, B. (1990). Visualisation and cognition: Thinking with eyes and hands. In M. E. Lynch \& S. Woolgar (Eds.), Representation in Scientific Practice. Cambridge, MA: MIT Press.

Moro, C. (2015). Material culture: Still 'terra incognita' for psychology today? Europe's Journal of Psychology, 11(2), 172-176. doi:10.5964/ejop.v11i2.995

Patil, I., Cogoni, C., Zangrando, N., Chittaro, L., \& Silani, G. (2014). Affective basis of judgmentbehavior discrepancy in virtual experiences of moral dilemmas. Social Neuroscience, 9(1), 94-107. doi:10.1080/17470919.2013.870091

Peralta, C., \& Moultrie, J. (2010). Collaboration between designers and scientists in the context of scientific research: A literature review. In D. Marjanovic, M. Storga, N. Pavovic, \& N. Bojcetic (Eds.), DS 60: Proceedings of DESIGN 2010, the 11 th International Design Conference, Dubrovnik, Croatia (pp. 1643-1652). Glasgow, UK: The Design Society. Retrieved from https://www.designsociety.org/publication/29510/collaboration_between_designers_and_scientists_in_the_context_of_scientific_research_a_literature_review

Piaget, J. (1976). Piaget's theory. In B. Inhelder, H. H. Chipman, \& C. Zwingmann (Eds.), Piaget and his school: A reader in delevopmental psychology (pp. 11-23). New Yor, NY: Springer-Verlag.

Small, C. (1998). Musicking. Middletown, CT: Wesleyan University Press.

Terbeck, S., \& Francis, K. B. (in press). We should if we could, but we can't. Experimental problems with moral enhancement. In M. Hauskeller (Ed.), Moral Enhancement. Cambridge, UK: Cambridge University Press.

Thomson, J. J. (1976). Killing, letting die, and the trolley problem. Monist, 59(2), 204-217. 


\section{First response to "Thinkering through Experiments: Nurturing Transdisciplinary Approaches to the Design of Testing Tools" by Alexandra Marian, Paula Moldovan, Beatrix Perde, Roxana Vescan, Calin Hopsitar, \& Doris Rogobete}

\section{Implications for Measurement in Morality Research}

According to Jonathan Haidt (2001), moral judgements are based upon intuitiona fast and unconscious process that is heavily dependent on context. Reasoning comes afterwards and sustains our judgements with well-constructed arguments. As such, "moral judgements should be studied as an interpersonal process" (Haidt, 2001, p. 814), because oftentimes our moral responses and actions are influenced by the cultural norms that shape our current thinking. Therefore, it is important to incorporate emotions, actions and the wider context when we are trying to study morality and moral decision-making in the lab. In the end, this is why these kinds of decision are so hard to make: the person facing a moral dilemma is completely involved in the situation, both cognitively and emotionally. As an example, we might consider the Stanford prison experiment (Zimbardo, Haney, Banks, \& Jaffe, 1971). Although controversial, it offered valuable information on how the ecological validity of the experimental context (the 'prison-like' setting, the uniforms of the guards, the rules that were set, etc.) contributed to the shocking decisions made by the 'guards.' In this case, the complete immersion of the participants in the set blurred the lines between reality and 'fantasy,' permitting an insight into how power and authority distorts our thinking and moral actions.

\section{General Implications for Research Methodology}

The research conducted by the three authors demonstrates the importance of creating experimental contexts and tools that can produce a 'natural' response from the participant. Given that a person learns and encodes his/her experiences using the sensory-motor neural networks (and others), as the embodied cognition approach states (Barsalou, 2008), recreating the elements of a real situation might produce a similar activation pattern in the brain, thus eliciting a more authentic response from the participant. Therefore, experimental contexts and tools that closely resemble those found in real-life might offer the best of both worlds: they improve the reliability and validity of the participants' responses, while still having a more controlled setting that allows us to draw more solid or causal conclusions. Moreover, the process of creating a research tool offers a good opportunity for the researcher to anticipate variables that might influence the result of the test. While involved in 'the making' of tools, the experimenter becomes a part of the process. And this might make him more cognizant about how the testing situation would go and how the person being tested would react. 
If we talk about testing children (preschoolers or infants), the process of creating appropriate tools and experimental contexts becomes even more challenging. Young children do not always have the means to answer our questions nicely or to complete a task according to our instructions. When finding himself in such circumstances, the experimenter is 'forced' to create an experimental environment that can sustain a natural response from the child. Sometimes, we even 'become' the child in order to understand his behavior and the processes that sustain it (see Yu \& Smith, 2013, for an example).

\section{Rerefences}

Barsalou, L. W. (2008). Grounded cognition. Annual Review of Psychology, 59, 617-645. doi:10.1146/annurev.psych.59.103006.093639

Haidt, J. (2001). The emotional dog and its rational tail: A social intuitionist approach to moral judgment. Psychological Review, 108(4), 814-834. doi:10.1037//0033-295X.108.4.814

Zimbardo, P. G., Haney, C., Banks, W. C., \& Jaffe, D. (1971). The Stanford prison experiment: A simulation study of the psychology of imprisonment conducted August 1971 at Stanford Univesrity. Retrieved from https://web.stanford.edu/dept/spec_coll/uarch/exhibits/Narration.pdf

Yu, C., \& Smith, L. B. (2013). Joint attention without gaze following: Human infants and their parents coordinate visual attention to objects through eye-hand coordination. PLoS ONE, 8(11), 1-10. doi:10.1371/journal.pone.0079659 


\section{Second response to "Thinkering through Experiments: Nurturing Transdisci- plinary Approaches to the Design of Testing Tools" by Joanna Griffin}

The "footbridge dilemma," or "trolley problem," which is the inspiration for the "thinkering" experiments carried out by the co-authors, has a strong aesthetic. It is a moral psychology problem with a history, even folklore, attached to it. It has a certain timelessness: A tool from the 1960s and 70s associated with work by Phillipa Foot and Judith Thompson, but doubtless drawing on much older stories and riddles that involve listeners, participants and interlocutors in deep engagements with moral questions and contexts. It is a "classic" moral psychology test, coming from the same roots perhaps as the infamous Milgram experiment in which participant "experimenters" were asked to increase the electric shock given to so-called "learners." In that test a theater of authority was created through the materiality of lab coats, control panels, the separation of experimenter from subject as well as through the guiding performance of the scientist-organizers. It highlighted how surreptitious forms of violence become possible when the test is bracketed off from reality and was apparently motivated by Eichmann's acquiescence to violence when he followed orders that allowed holocaust genocide. From my perspective, as an artist, the "footbridge dilemma," has all the traits of a surrealist ruse: it involves potential violence and questions of morality, both attractive to 1930s Surrealist group sensibilities and, crucially, a degree of detachment from everyday reality.

In the redesign of the test you describe, I was struck by the explanation of how making opened your sense of the participant experience of the moral dilemma. The test became a "figment of the making," its constitution, and in particular, your own bonds with the experiment, became tangible "allowing for a more thorough construction of the participant's experience." It is these questions of experience and access to experience and how access shifts through making or other creative activities that I want to briefly focus on and point to a text by Sundar Sarukkai in a dialogue anthology with social anthropologist Gopal Guru, The Cracked Mirror: An Indian Debate on Experience and Theory (2012). Sarrukkai and Guru debate who has the moral right to theorize another's experience. Their moral question focuses on whether a nonDalit can speculate on what the experience of a Dalit person is, when the prerequisite for being of this community is that there is no escape from caste: To dip in and out as an ethnographer, Guru argues, is immoral. Sarukkai responds that if our experiences are co-constructed and shared to some extent, there is moral ground to interpret, and he asks: "Is an individual the author of her experiences?" (Guru, 2012, p. 38). This discussion helped me to unpack the experiences of those who made the Chandrayaan spacecraft, also an experimental scientific instrument (Griffin, 2014). It also bears on the paper's insights into "thinkering," because the question of what constitutes an experience is embroiled in questions of "what is the test?" and where 
the edges of the experiment appear to be. Your collaboration opens up questions of who authors and interprets the test and in what ways the roles of designer, participant and experimenter are shared, all potent moral frontiers for science.

\section{References}

Guru, G., \& Sarukkai, S. (2012). The cracked mirror: An Indian debate on experience and theory. New Delhi, India: Oxford University Press.

Griffin, J. (2014). Experience and viewpoints in the social domain of space technology (Doctoral dissertation). Plymouth University, Plymouth, UK. 